\title{
High-Performance Liquid Chromatographic Separation of Metal Ions with 2-Hydroxy-5-sulfoaniline- $\boldsymbol{N}$-salicylidene
}

\author{
Michio ZeNKI and Kazue INOUE \\ Department of Chemistry, Faculty of Science, Okayama University of Science, \\ Ridai-cho, Okayama 700, Japan
} Keywords High-performance liquid chromatography, 2-hydroxy-5-sulfoaniline- $N$-salicylidene, precolumn
complexation, spectrophotometric detection

High-performance liquid chromatography (HPLC) for the separation and determination of metal ions as their chelates with organic reagents has received increasing attention in recent years. ${ }^{1-3}$ An attractive approach is the precolumn method, in which the metal chelate formation is completed prior to the separation and determination by HPLC. In most cases, a reagent forms less soluble chelates in water, and the chelates and the reagent itself are held strongly on the analytical column. Thus an organic modifier such as methanol, acetonitrile or a surfactant is added to the mobile phase in order to keep the chelates in solution or to elute them from the column. Organic solvents for HPLC purposes are, however, expensive and must be treated after use. Moreover, organic modifiers have different absorbances and refractive indexes from water, and these make baseline noises and troublesome system peaks., ${ }^{4,5}$ The ideal mobile phase for the reversed-phase HPLC should be an aqueous solution. In this paper, a sulfonated derivative of salicylidene $o$-aminophenol ${ }^{6}$, 2-hydroxy-5sulfoaniline- $N$-salicylidene (HSS) has been investigated as a precolumn chelating reagent for the reversed-phase HPLC with spectrophotometric detection. Neat aqueous solutions ( $0.05 \mathrm{M}$ acetate buffer, $\mathrm{pH}$ 5.0) have been used in both complexation and chromatographic elution.

\section{Experimental}

\section{Apparatus}

The chromatographic system consisted of a Shimadzu LC-6A pump unit, an SPD-6A spectrophotometric detector, a Rheodyne 7125 sample injector with a $100-\mu l$ loop and a Tosoh CO-8011 column oven. A LiChrosorb RP-18 column ( $150 \times 4 \mathrm{~mm}$ i.d., $5-\mu \mathrm{m}$ spherical octadecyl silica) was used. The $\mathrm{pH}$ measurements were carried out with a Horiba E-11 pH meter.

\footnotetext{
Reagents

HSS was synthesized and purified as described previously. ${ }^{7}$ Elementary analysis of the resulting
}

compound gave the following results: Calcd. for $\mathrm{C}_{13} \mathrm{H}_{10} \mathrm{O}_{5} \mathrm{NSK} \cdot \mathrm{H}_{2} \mathrm{O}: \mathrm{C}, 44.7 ; \mathrm{H}, 3.44 ; \mathrm{N}, 4.01 \%$. Found: C, $45.0 ; \mathrm{H}, 4.26 ; \mathrm{N}, 4.01 \%$. Solutions of $2.5 \times 10^{-3} \mathrm{M}$ $\left(\mathrm{M}=\mathrm{mol} \mathrm{dm} \mathrm{dm}^{-3}\right) \mathrm{HSS}$ in distilled water were prepared daily. Standard solutions of metal were prepared by dilution of commercially available standards $(1000 \mu \mathrm{g} /$ $\mathrm{cm}^{3}$, Wako Pure Chemicals) for AAS. The mobile phase was prepared by mixing $0.05 \mathrm{M}$ sodium acetate and acetic acid solution, this was adjusted to $\mathrm{pH}$ 5.0. The mobile phase was filtered through a $0.45-\mu \mathrm{m}$ cellulose acetate membrane filter and degassed by ultrasonication before use. All aqueous solutions were prepared with distilled and deionized water, purified with a Millipore Milli- $Q$ system.

\section{Procedure}

An aqueous solution containing $\mathrm{Al}^{3+}, \mathrm{Cr}^{6+}, \mathrm{Cu}^{2+}, \mathrm{Ga}^{3+}$ and $\mathrm{V}^{5+}$ was taken in a $50 \mathrm{ml}$ plastic volumetric flask. To this solution, $10 \mathrm{ml}$ of $2.5 \times 10^{-3} \mathrm{M}$ HSS and $5 \mathrm{ml}$ of $0.5 \mathrm{M}$ acetate buffer solution ( $\mathrm{pH} 5.0$ ) were added, and this mixture was diluted up to $50 \mathrm{ml}$ with water. After 30 min standing, a $100-\mu l$ aliquot of the solution was injected into the HPLC column through a $100-\mu 1$ sample loop. HSS metal chelates were eluted with $0.05 \mathrm{M}$ acetate solution (pH 5.0) at a flow rate of $1.0 \mathrm{ml} / \mathrm{min}$ and detected at $405 \mathrm{~nm}$. By measuring the peak height, the amounts of each metal were determined.

\section{Results and Discussion}

\section{Spectrophotometric properties of HSS-metal chelates}

HSS reacts with several metal ions to produce yellow anionic chelates. The optimum $\mathrm{pH}$ range for the chelate formation lay around 4-7, and color development proceeds immediately. The absorption maxima and molar absorption coefficients $(\varepsilon)$ of HSS-metal chelates at pH 5.0 were $405 \mathrm{~nm}$ for $\mathrm{Al}^{3+}(\varepsilon=19000), 420 \mathrm{~nm}$ for $\mathrm{Cr}^{6+}(\varepsilon=12000), 405 \mathrm{~nm}$ for $\mathrm{Cu}^{2+}(\varepsilon=16000), 415 \mathrm{~nm}$ for $\mathrm{Ga}^{3+}(\varepsilon=32000)$ and $420 \mathrm{~nm}$ for $\mathrm{V}^{5+}\left(\varepsilon=140001 \mathrm{~mol}^{-1}\right.$ $\mathrm{cm}^{-1}$ ). A detection wavelength between 400 and $430 \mathrm{~nm}$ 
was suitable, whereas the absorbance of HSS itself was small $\left(\varepsilon<1001 \mathrm{~mol}^{-1} \mathrm{~cm}^{-1}\right.$, at $\left.405 \mathrm{~nm}\right)$. The absorption coefficients of all metal chelates $>10^{4} \mathrm{~mol}^{-1} \mathrm{~cm}^{-1}$, are sufficient to ensure the $\mathrm{ng} / \mathrm{cm}^{3}$ level detection of metal ions. On the other hand, HSS chelates with $\mathrm{Al}^{3+}$ and $\mathrm{Ga}^{3+}$ show intense greenish fluorescence. ${ }^{8}$ The simultaneous determination of $\mathrm{Al}^{3+}$ and $\mathrm{Ga}^{3+}$ with fluorometric detection by precolumn reversed-phase HPLC is also possible. ${ }^{9}$

\section{Mobile phase}

Solutions of acetate, phosphate, perchlorate, sulfate, tartrate, malate, borate, oxalate, malonate, formate, propionate, butyrate, citrate $(0.01,0.05$ and $0.1 \mathrm{M})$ were investigated as both the buffer solution of complexation and the mobile phase under $\mathrm{pH}$ 5.0. All solutions except borate showed elution behavior, but gave small, broad and tailed peaks of HSS-metal chelates. In the case of using tartrate, oxalate or propionate solution, the peaks of chelates were overlapped $\left(\mathrm{Al}^{3+}\right.$ and $\mathrm{Ga}^{3+}, \mathrm{Cr}^{6+}$ and $\mathrm{V}^{5+}$, and $\mathrm{Ga}^{3+}$ and $\mathrm{V}^{5+}$, respectively), and did not resolve successfully. Acetate, malate and formate were found to be suitable with respect to the resolution and the detection sensitivity of the metal chelates, and acetate was used throughout in this work. The elution order of HSS chelates was $\mathrm{Cr}^{6+}, \mathrm{Al}^{3+}, \mathrm{Ga}^{3+}, \mathrm{V}^{5+}$ and $\mathrm{Cu}^{2+}$ and did not change with the difference of mobile phase used except for butyrate solution (where the order is $\mathrm{Cr}, \mathrm{Al}$, $\mathrm{Ga}, \mathrm{Cu}$ and $\mathrm{V}$ ).

\section{Chromatogram}

A typical chromatogram obtained for a solution containing the $\mathrm{Al}^{3+}, \mathrm{Cr}^{6+}, \mathrm{Cu}^{2+}, \mathrm{Ga}^{3+}$ and $\mathrm{V}^{5+}$ chelates is shown in Fig. 1. All five metal chelates were well resolved. The detection was done at $405 \mathrm{~nm}$, where the peak of reagent (HSS) could not be observed in the chromatogram. This is due to the low absorptivity of the reagent ${ }^{7}$ and no appearance of the reagent peak is advantageous for measurement of metal chelates.

HSS reacts with other metal ions ${ }^{7,10}$ such as $\mathrm{In}^{3+}, \mathrm{Mo}^{6+}$, $\mathrm{W}^{6+}$ and $\mathrm{Zr}^{4+}$, but these metal chelates are probably decomposed in the HPLC column owing to their labile nature. The additions of HSS to the mobile phase may permit the chromatographic separation of these chelates, but this complicates the detection of the chelates in the elution.

\section{Effect of $p H$}

The $\mathrm{pH}$ of solutions for both complexation and elution were adjusted in the range 3.0-6.0; then the effect of pH on the resolution of HSS chelates was investigated (Fig. 2). The capacity factor $\left(k^{\prime}\right)$ of $\mathrm{Al}^{3+}$ and $\mathrm{Ga}^{3+}$ chelates increased gradually with increasing the $\mathrm{pH}$, but the other chelates were unchanged. On the other hand, the peak height of $\mathrm{Al}^{3+}$ and $\mathrm{Ga}^{3+}$ chelates decreased with increasing $\mathrm{pH}$ due to the hydrolysis, whereas the peak height of $\mathrm{V}^{5+}$, and $\mathrm{Cu}^{2+}$ chelates increased in the $\mathrm{pH}$ range 4-6. The peak height of $\mathrm{Cr}^{6+}$ was independent of $\mathrm{pH}$. The peak of $\mathrm{Al}^{3+}$ and $\mathrm{Ga}^{3+}$ chelates could not observed

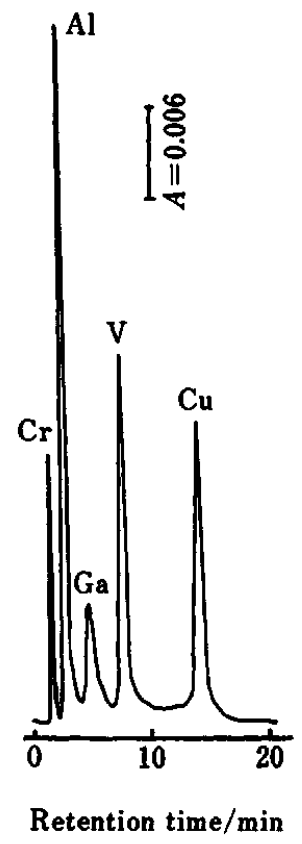

Fig. 1 Chromatogram of HSS metal chelates. Column: LiChrosorb RP-18 (150×4 mm i.d.). Mobile phase: $0.05 \mathrm{M}$ acetate $(\mathrm{pH} 5.0)$. Flow rate: $1.0 \mathrm{ml} / \mathrm{min}$. Detection: at $405 \mathrm{~nm}$. Metal ion: $40 \mathrm{ng}\left(\mathrm{Al}^{3+}, \mathrm{Cr}^{6+}\right), 100 \mathrm{ng}\left(\mathrm{Cu}^{2+}, \mathrm{Ga}^{3+}\right.$, $\left.\mathrm{V}^{5+}\right)$.

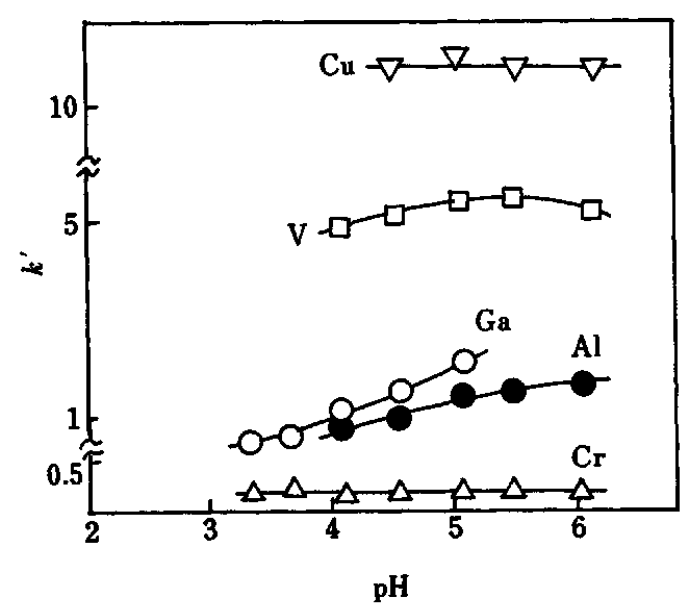

Fig. 2 Effect of $\mathrm{pH}$ on capacity factor $\left(k^{\prime}\right)$. Chromatographic conditions were the same as given in Fig. 1.

below pH 4.0 and 3.0, respectively, because the protonation of the HSS was predominant. It is evident that highly selective determinations are possible by choosing the $\mathrm{pH}$ of the eluent and the buffer solution of complexation. In this work, the $\mathrm{pH}$ of both solutions were adjusted to 5.0 using acetate, so five metal chelates were observed in the chromatogram and could be separated successfully.

In another set of experiments, the effect of the concentration of acetate on the elution behavior of the 
metal chelates was investigated at the constant $\mathrm{pH}$ of 5.0. The $k^{\prime}$ increased with increasing concentration of acetate up to $0.1 \mathrm{M}$, then decreased gradually. For example, the $k^{\prime}$ of $\mathrm{Cu}^{2+}$ chelate increased from 9.0 to 11.5 when the concentration of acetate changed from 0.01 to $0.1 \mathrm{M}$. On the other hand, the peak height of metal chelates decreased with increasing the concentration of acetate (20\% decreased for $\mathrm{Cu}^{2+}$ as before); therefore, $0.05 \mathrm{M}$ acetate adjusted to $\mathrm{pH} 5.0$ was used.

\section{Effect of HSS concentration}

The effect of HSS concentration in sample solutions was investigated. The retention times of all chelates tested were independent of the concentration of HSS in the sample solution. The peak heights of $\mathrm{Cr}^{6+}, \mathrm{Ga}^{3+}, \mathrm{V}^{5+}$ and $\mathrm{Cu}^{2+}$ chelates were independent on HSS concentration, but that of $\mathrm{Al}^{3+}$ increased markedly in the concentration range $1.0 \times 10^{-4}-5.0 \times 10^{-4} \mathrm{M}$. Sometimes the color development of $\mathrm{Al}^{3+}$ with organic reagents is very slow; then heating of sample solution to $70-90^{\circ} \mathrm{C}$ is required.11,12 Therefore, the effects of temperature and standing time on the formation of the HSS chelates were investigated. It was found that if a higher concentration of HSS $\left(>3 \times 10^{-4} \mathrm{M}\right)$ was added to the sample solution, the formation of Al-chelate, as well as those of the other chelates, proceed fast enough to produce sufficient stable complexes, so that it was not necessary for the sample solution to maintain a evaluated temperature nor to stand for a long time. The concentration of HSS in sample solution was decided to be $5.0 \times 10^{-4} \mathrm{M}$; the solution was kept for $30 \mathrm{~min}$ before injection onto the column.

\section{Interferences}

The effect of possible interferences was studied by adding various foreign ions to the sample solution before chromatographic separation. Alkali metals, alkaline earth metals, $\mathrm{As}^{3+}, \mathrm{Be}^{2+}, \mathrm{Cd}^{2+}, \mathrm{Co}^{2+}, \mathrm{Cr}^{3+}, \mathrm{Cu}^{+}, \mathrm{Fe}^{2+}, \mathrm{Fe}^{3+}$, $\mathrm{La}^{3+}, \mathrm{Mn}^{2+}, \mathrm{Mo}^{6+}, \mathrm{Ni}^{2+}, \mathrm{Pb}^{2+}, \mathrm{Sb}^{3+}, \mathrm{Sc}^{3+}, \mathrm{Se}^{4+} \mathrm{Sn}^{2+}, \mathrm{Ti}^{4+}$, $\mathrm{Y}^{3+}$ and $\mathrm{Zn}^{2+}$ ions were tested. A 10-fold excess of these ions showed no peaks and gave no interference $(<5 \%$ change in peak height) with the separation and determination of $\mathrm{Al}^{3+}, \mathrm{Cr}^{6+}, \mathrm{Cu}^{2+}, \mathrm{Ga}^{3+}$ and $\mathrm{V}^{5+}$. Only $\mathrm{Fe}^{3+}$ showed an elution peak which was overlapped with the peak of $\mathrm{V}^{5+}$ chelate. It was not possible to improve the resolution of iron chelate by adding a suitable masking agent, such as triethanolamine, nitriloacetate and Tiron. Large amounts (100-fold) of common anions such as $\mathrm{Cl}^{-}, \mathrm{Br}^{-}, \mathrm{NO}_{3}{ }^{-}, \mathrm{HCO}_{3}{ }^{-}$and $\mathrm{SO}_{4}{ }^{2-}$ could be tolerated, but $\mathrm{F}^{-}$and $\mathrm{H}_{2} \mathrm{PO}_{4}^{-}$reduced the peak height of $\mathrm{Al}^{3+}$ by 80 and $60 \%$, respectively. But a 10 -fold excess of $\mathrm{H}_{2} \mathrm{PO}_{4}^{-}$and the same amount of $\mathrm{F}^{-}$caused no interference.

\section{Calibration}

In order to examine the potential of the technique for the determination of metal ions, calibration curves were prepared for the five tested ions by measuring the peak height. Good linear calibration curves were obtained over the concentration range $0.1-1.0 \mu \mathrm{g} / \mathrm{cm}^{3}$ for $\mathrm{Al}^{3+}$ and $0.2-3.0 \mu \mathrm{g} / \mathrm{cm}^{3}$ for $\mathrm{Cr}^{6+}, \mathrm{Cu}^{2+}, \mathrm{Ga}^{3+}$ and $\mathrm{V}^{5+}$. The proposed method is highly sensitive to $\mathrm{Al}^{3+}$ whose detection limit is $40 \mathrm{ng} / \mathrm{cm}^{3}$. The detection limit for $\mathrm{V}^{5+}$ is $60 \mathrm{ng} / \mathrm{cm}^{3}$ and $100 \mathrm{ng} / \mathrm{cm}^{3}$ for $\mathrm{Cr}^{6+}, \mathrm{Cu}^{2+}$ and $\mathrm{Ga}^{3+}$ at a signal-to-noise ratio of 3 . The reproducibility of the present method was investigated for $0.4 \mu \mathrm{g} / \mathrm{cm}^{3}$ of $\mathrm{Al}^{3+}$ and $1 \mu \mathrm{g} / \mathrm{cm}^{3}$ of $\mathrm{Cu}^{2+}$ and $\mathrm{V}^{5+}$. The relative standard deviations were $2.1 \%$ for $\mathrm{Al}^{3+}, 5.4 \%$ for $\mathrm{Cu}^{2+}$ and $3.8 \%$ for $\mathrm{V}^{5+}$ in five replicate determinations.

\section{References}

1. H. Veening and B. R. Willeford, Adv. Chromatogr., 22, 117 (1983).

2. J. W. O'Laughlin, J. Liq. Chromatogr., 7, 127 (1984).

3. K. Robards, P. Starr and E. Patsalides, Analyst [London], 116, 1247 (1991).

4. P. E. Jackson and P. R. Haddad, J. Chromatogr., 346, 125 (1985).

5. S. Levin and E. Grushka, Anal. Chem., 58, 1602 (1986).

6. R. M. Dagnall, R. Smith and T. S. West, Talanta, 13, 609 (1966).

7. M. Zenki, K. Hori and N. Enomoto, Bunseki Kagaku, 27, 570 (1978).

8. K. Morishige, Anal. Chim. Acta, 72, 295 (1974).

9. K. Inoue and M. Zenki, Bunseki Kagaku, 42, 805 (1993).

10. M. Deguchi, N. Ebisuya and K. Morishige, Bunseki Kagaku, 33, 678 (1984).

11. H. Hoshino, K. Nakano and T. Yotsuyanagi, Analyst [London], 115, 133 (1990).

12. Y. Akama, A. Tong and S. Tanaka, Chem. Lett., 1989, 963. 